\title{
Performance Analysis of Routing Protocol for Improvement Quality of Service (QoS) in Wireless Sensor Network
}

\author{
Rakesh Kumar Saini ${ }^{1}$ and Ritika ${ }^{2}$ \\ ${ }^{1,2}$ Department of Computer Science and Application, DIT University, Dehradun \\ Uttrakhand, India \\ rk.saini@dituniversity.edu.in,hod.mca@dituniversity.edu.in
}

\begin{abstract}
Wireless Sensor Network has many sensor nodes that are used to monitor the physical and environmental condition such as Vibration, Temperature Sound and so on. In Wireless sensor network all sensor cooperately pass their data to the base station from where data are transmitted via satellite or internet to the base station. Wireless sensor network has some constraints like power or energy is limited, computational capability is limited, storage capability is limited. Energy efficiency of sensor nodes is very big issue in wireless sensor network because sensor nodes have low energy. To improve energyefficiency of sensor nodes various routing protocols have been proposed in wireless sensor network like Cluster based routing protocols-LEACH (Low-Energy Adaptive Clustering Hierarchy), LEACH-C (Low-Energy Adaptive Clustering HierarchyCentralized), EEPSC (Energy-Efficient Protocol with Static Clustering), Cross-layered modification technique and other routing protocols like AODV, DSR, Bellman Ford, $D S D V$ and DYMO Routing protocols. So in this work we try to analyze the performance of AODV, DYMO and DSR routing protocol for improvement Quality of Service $(Q o S)$ in Wireless Sensor Network. The parameters used for the performance analysis include average jitter, throughput, average end to end delay.
\end{abstract}

Keywords: Sensor nodes, Wireless Sensor Network, AODV, DSR, DYMO, Qualnet 5.0.2

\section{Introduction}

Wireless sensor network has many sensor nodes that are interconnected by wireless communication channels. Sensor node is a small device that is used to monitor the physical and environmental condition such as temperature, sound and any movement in the sensing field. Sensor node senses the data and sends to nearest sensor node and all sensor nodes corporately pass their data to the base station via internet or satellite. Nowadays wireless sensor networks are popular and their applications are used by our military for environment monitoring. Wireless sensor networks are used for other purpose like home security, earthquake warning. The purpose of WSNs is to collaboratively sense, collect and process the information of the objects detected in the monitored area, and then sends it to the Base Station. The applications of WSNs are very extensive, for example, military application, environmental monitoring, health info, Smart home. Despite the infinite scopes of wireless sensor networks, they are limited by the node battery lifetime. Once they are deployed, the network can keep operating while the battery power is adequate. This is critical point to be considered as it is almost impossible to replace the node battery once deployed over an inaccessible area. Such constraints combined with a typical deployment of large number of sensor nodes, have posed many challenges to the design and management of sensor networks and necessitate energy-awareness at all layers of networking protocol stack $[1,2]$. The main task of a sensor node in a sensor field is to detect events, perform quick local data processing, and then transmit the data to 
base station [3]. In this paper we study and analysis different routing protocols like AODV (Ad-hoc On-demand Distance Vector Routing) and Dynamic Source Routing (DSR) Routing protocols and as well as DYMO for improvement quality of service (QoS) in Wireless sensor network. Parameters of quality of service are average jitter, throughput and average end to end delay.

\section{Wireless Sensor Network}

A wireless sensor network consists distributed autonomous sensors nodes that are used to monitor physical or environmental conditions, such as temperature, sound, vibration, pressure and to cooperatively pass their data to the base station [2]. The more modern networks are bi-directional, also enabling control of sensor activity [3]. The development of wireless sensor networks was motivated by military applications such as battlefield surveillance; today such networks are used in many industrial and consumer applications, such as industrial process monitoring and control, machine health monitoring, and so on. The WSN is built of "nodes" - from a few to several hundreds or even thousands, where each node is connected to one (or sometimes several) sensors. Each such sensor network node has typically several parts: a radio transceiver with an internal antenna or connection to an external antenna, a microcontroller, an electronic circuit for interfacing with the sensors and an energy source, usually a battery or an embedded form of energy harvesting. A sensor node might vary in size from that of a shoebox down to the size of a grain of dust, although functioning "motes"(demo video) of genuine microscopic dimensions have yet to be created. The cost of sensor nodes is similarly variable, ranging from hundreds of dollars to a few pennies, depending on the complexity of the individual sensor nodes. Size and cost constraints on sensor nodes result in corresponding constraints on resources such as energy, memory, computational speed and communications bandwidth. The topology of the WSNs can vary from a simple star network to an advanced multi-hop network. The wireless sensor node, being a microelectronic device, can only be equipped with a limited power source $(<0.5 \mathrm{Ah}, 1.2$ V). In some application scenarios, replenishment of power resources might be impossible [5]. Sensor node lifetime, therefore, shows a strong dependence on battery lifetime. In a multihop ad hoc sensor network, each node plays the dual role of data originator and data router. The malfunctioning of a few nodes can cause significant topological changes and might require rerouting of packets and reorganization of the network. Hence, power conservation and power management take on additional importance. It is for these reasons that researchers are currently focusing on the design of power-aware protocols and algorithms for sensor networks. In Wireless Sensor network, all sensor nodes move from one location to another location [7]. In this paper we analyze mobility of sensor nodes in Wireless Sensor Network. The base stations are one or more components of the WSN with much more computational, energy and communication resources. They act as a gateway between sensor nodes and the end user as they typically forward data from the WSN on to a server. Other special components in routing based networks are routers, designed to compute, calculate and distribute the routing tables [8]. Many techniques are used to connect to the outside world including mobile phone networks, satellite phones, radio modems, long-range Wi-Fi links etc. Many base stations are ARM-based running a form of Linux. The main characteristics of a WSN include

1. There is no need of wire

2. Ability to cope with node failures

3. Mobility of nodes

4. Dynamic network topology

5. Self-organization

6. Heterogeneity of nodes 
7. Scalability to large scale of deployment

8. Performance as router by all nodes

9. Ease of deployment

10. Unattended operation

11. Low-power consumption

12. Ease of use

\section{Routing in WSN}

In wireless sensor network many routing protocol works for communication between sensor nodes. These routing protocols should be energy-efficient. There are some ondemand routing protocols in wireless sensor network. On-demand routing protocol do not maintain routing information at the sensor nodes if there is no communication. If a sensor node wants to send sense data to some another sensor node, then this protocol searches for the route in an on-demand manner and build the connection in order to transmit and receive the data. The route discovery usually occurs by flooding the route request packets throughout the network $[9,10]$. On demand routing protocols use two different processes to find and maintain routes: first is route discovery process and the second is route maintenance process. In this paper we analysis on-demand routing protocols like DSR, AODV, and DYMO.

\section{(a) AODV (Ad-hoc On-demand Distance Vector Routing)}

AODV is a reactive routing protocol based on DSDV.AODV is designed for networks with tens to thousands of sensor nodes. One feature of AODV is the use of a destination sequence number for each routing table entry [11]. The sequence number is created by the destination node. AODV uses routing tables, with one route entry per destination where each entry stores next hops towards destination. It broadcast route request (RREQ) packets and this RREQ is uniquely identified by the sender address, destination address and request ID.After processing the RREP packet the node forwards it toward the source. The node can later update its routing information if it discovers a better path or route.

\section{(b) DSR (Dynamic Source Routing)}

Dynamic Source Routing (DSR) is a Source routed on-demand routing protocol in Wireless sensor networks.DSR is a reactive routing protocol which is able to manage a WSNs without using periodic table update message like table driven routing protocols do.DSR uses source routing, which is a technique in which the sender of a packet determines the complete sequence of sensor nodes through which the node has travel.DSR was specifically designed for use in multi-hop wireless sensor networks. The Dynamic Source Routing protocol is a simple and efficient, highly reactive, routing protocol [10]. The Dynamic Source Routing protocol (DSR) allows any host to dynamically discover a source route to any destination in the network. In DSR the sender determines the whole path from the source to the destination node and deposits the addresses of the intermediate nodes of the route in the packets.

\section{(c) DYMO (Dynamic MANNET On demand)}

Dynamic MANET On-demand (DYMO) routing protocol is similar to AODV routing protocol and its benefits are similar to AODV routing protocol. Basically DYMO routing protocol easy to implement and DYMO is enhancement of AODV.DYMO is energyefficient routing protocol that are used both as a pro-active and as a reactive routing protocol. In DYMO route can be discovered by sensor node when they are needed. In DYMO routing protocol when sensor node discover route then sensor node send a route request(RREQ) message to the destination and then destination send routing reply(RREP) 
message to source sensor node. DYMO routing protocol contain two operations similar to AODV routing protocol that are: route discovery and route maintenance [13].

\section{Simulation Setup for Performance Analysis}

In this work 20 sensor nodes are considered, the initial position of these nodes are random in the $100 \mathrm{~m} \times 100 \mathrm{~m}$ Area. In this work all sensor nodes cooperately pass their data to the base station and from where data is forward via internet or satellite to the task manager node or end user which want to monitor sensing area.Deployement of large sensor nodes is very difficult in real so for analysis purpose of wireless sensor networks routing protocol we create a scenario of 20 sensor nodes.Qualnet 5.0.2 is used for the purpose of simulation, first we select AODV Routing protocol and check the performance of AODV.Next we select on demand DYMO routing protocol and check the performance of DYMO similarly we select DSR (Dynamic Source Routing) and check the performance of DSR.Parameters that are used in this simulation are shown in Table 1.

Table 1. Simulation Parameters

\begin{tabular}{|l|l|}
\hline \multicolumn{1}{|c|}{ Parameters } & \multicolumn{1}{c|}{ Qalues } \\
\hline Simulator & Qualnet 5.0.2 \\
\hline $\begin{array}{l}\text { Routing } \\
\text { protocols }\end{array}$ & 20 \\
\hline Number of nodes & $100 \mathrm{~m} * 100 \mathrm{~m}$ \\
\hline Simulation area & CBR \\
\hline Traffic types & Random node placement \\
\hline Node Placement & $120 \mathrm{sec}$ \\
\hline Simulation time & $2.4 \mathrm{Ghz}$ \\
\hline Channel frequency & Omni directional \\
\hline Antenna &
\end{tabular}

\section{Simulation}

For analysis purpose of Quality of Service (QoS) parameters in wireless sensor network we consider three routing protocols that are AODV, DYMO and DSR. For analyzing the performance of these routing protocols we create a scenario in Qualnet 5.0.2 simulator tool. Figure 1 show the scenario in which sensor nodes cooperately pass their data from one sensor node to another sensor node. A simulation performance is performed using Qualnet 5.0.2 simulator. In Figure 2 show the running simulation in which sensor nodes working together and forward data to another destination sensor node. 


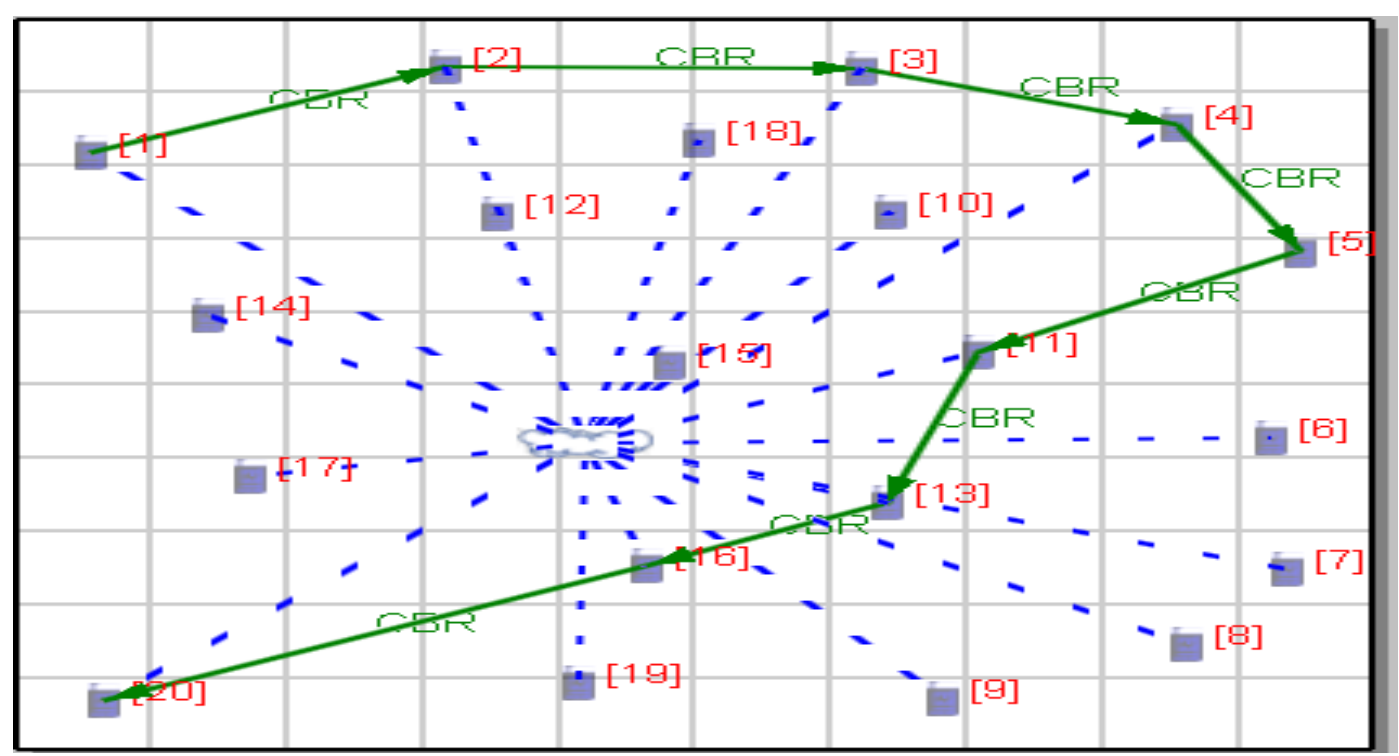

Figure 1. Simulation Setup

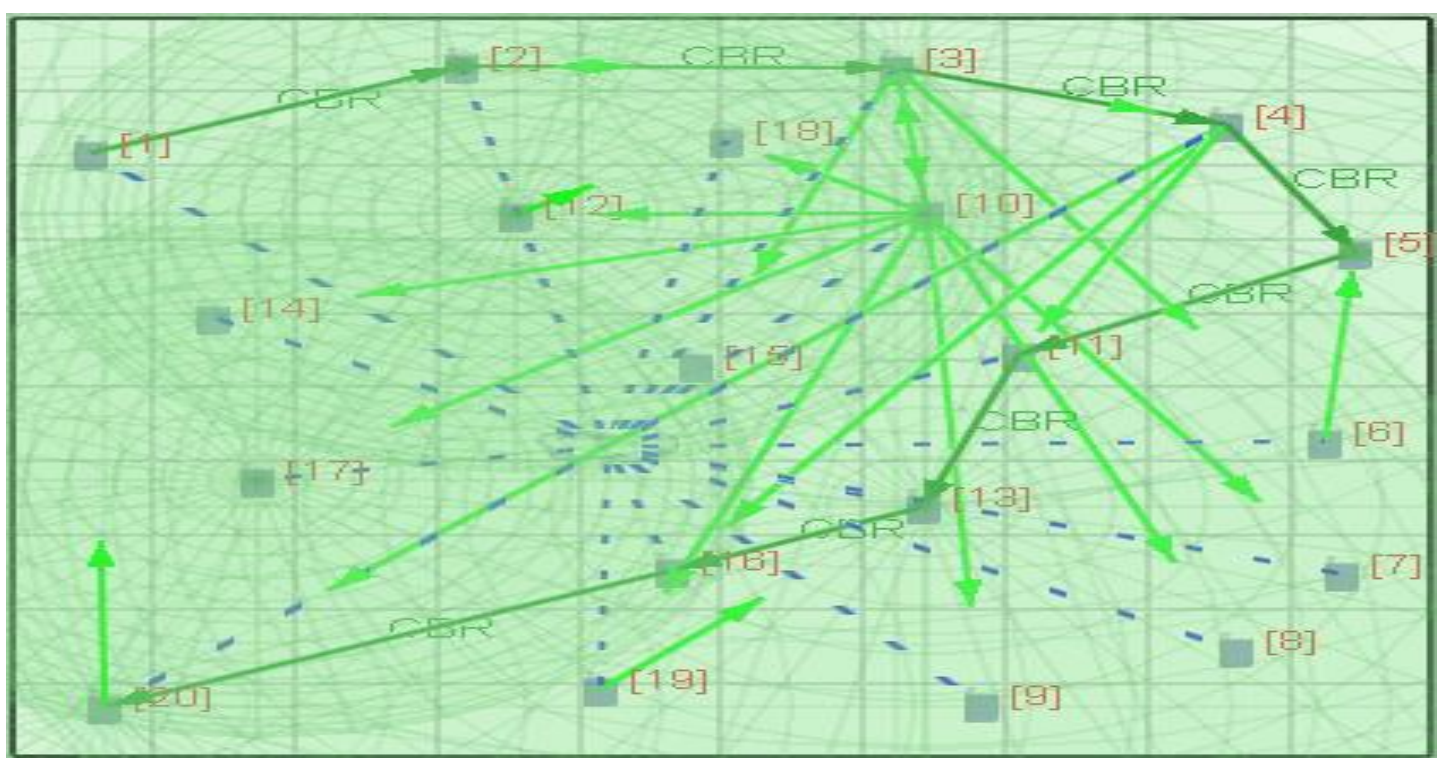

Figure 2. Running Simulation

\section{Simulation Result and Analysis}

The analyses of routing protocols are performed by the QualNet 5.0.2 network simulator. There are 20 sensor nodes placed randomly over the region of $100 \mathrm{~m} \times 100 \mathrm{~m}$. To analysis the performance of routing protocols (AODV, DYMO and DSR) the Quality of Service parameters are:

\section{i. $\quad$ Average jitter \\ ii. Throughput \\ iii. Average end to end delay}

\section{i. Average jitter}

Average jitter is the variation in delay by different data packets that reached the destination and can seriously affect the quality of audio and video and thus an unwanted parameter. By result analysis of three routing protocol we find that the average jitter is 
high of DSR, then, it is DYMO and then AODV. Figure (3) Show Average jitter of three routing protocol AODV (In Figure 3 (A)), DYMO (In Figure 3 (B)) and DSR (In Figure $.3(\mathrm{c}))$.

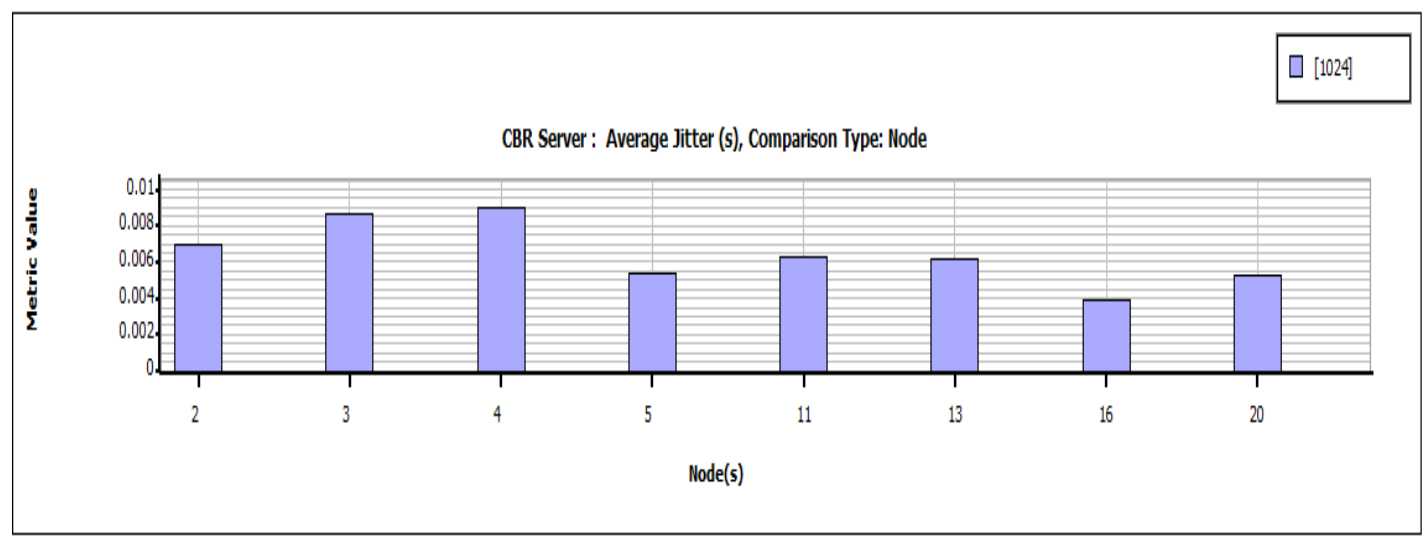

Figure 3. (A) Average Jitpter (AODV)

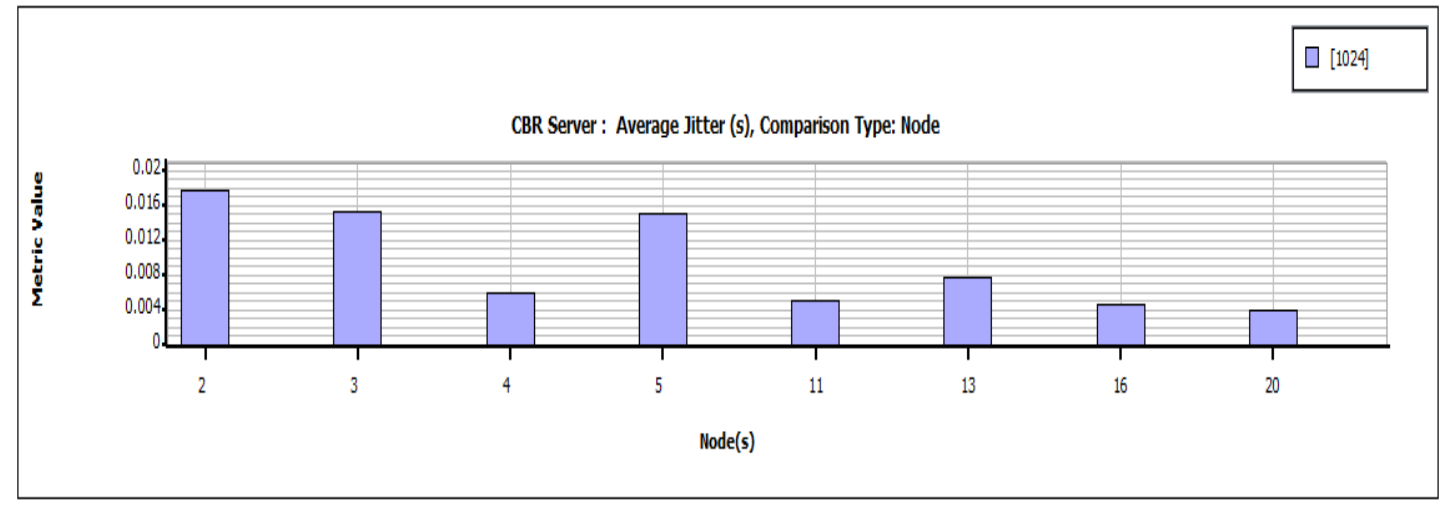

Figure 3. (B) Average Jitter (DYMO)

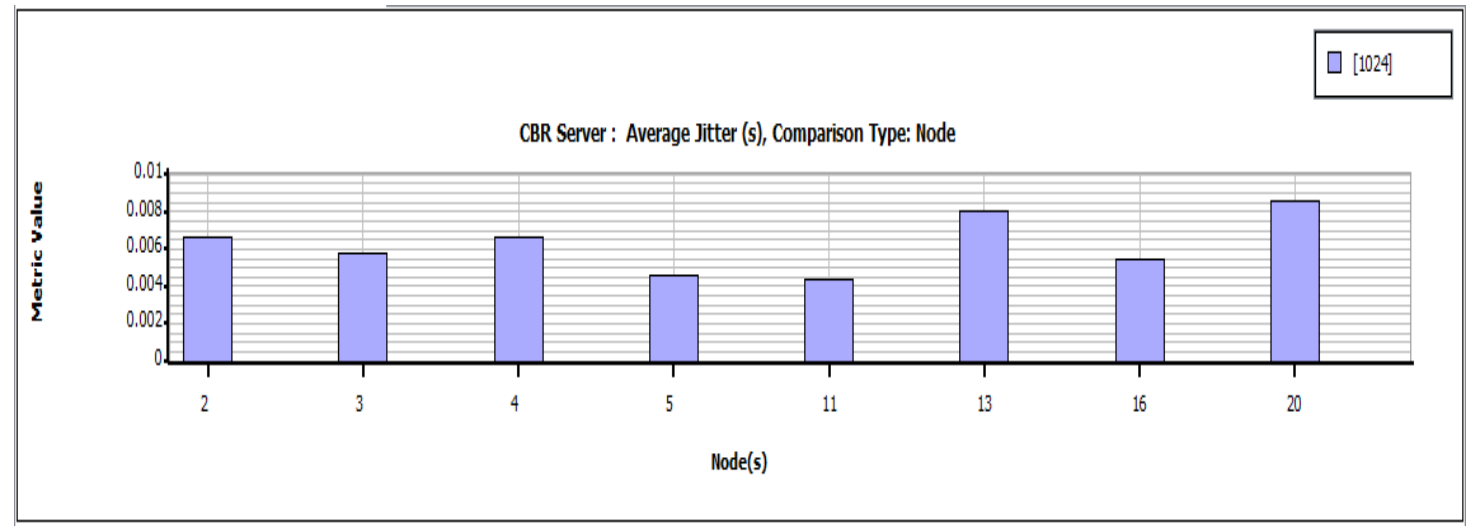

Figure 3.(C) Average Jitter (DSR)

\section{ii. Throughput}

Throughput is the average rate of successful message delivery in a communication channel. This data may be delivered over a physical or logical link, or pass through a certain network [14]. Figure (4) Show Throughput of three routing protocol AODV (Figure 4 (A)), DYMO (Figure 4 (B)) and DSR (Figure 4(c)). 


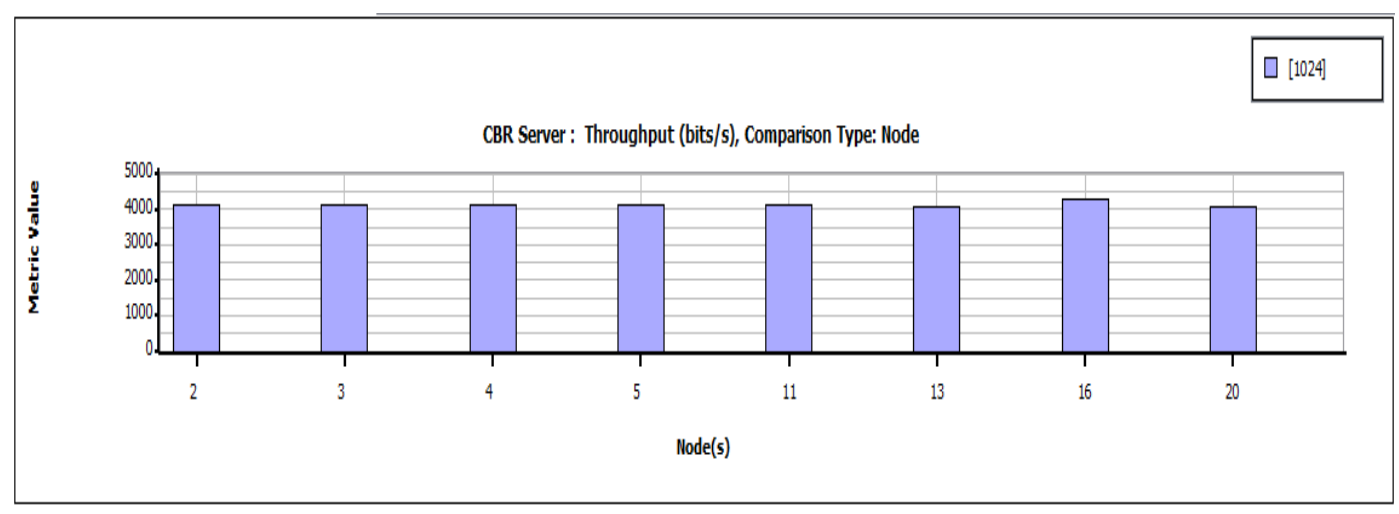

Figure 4. (A) Throughput (AODV)

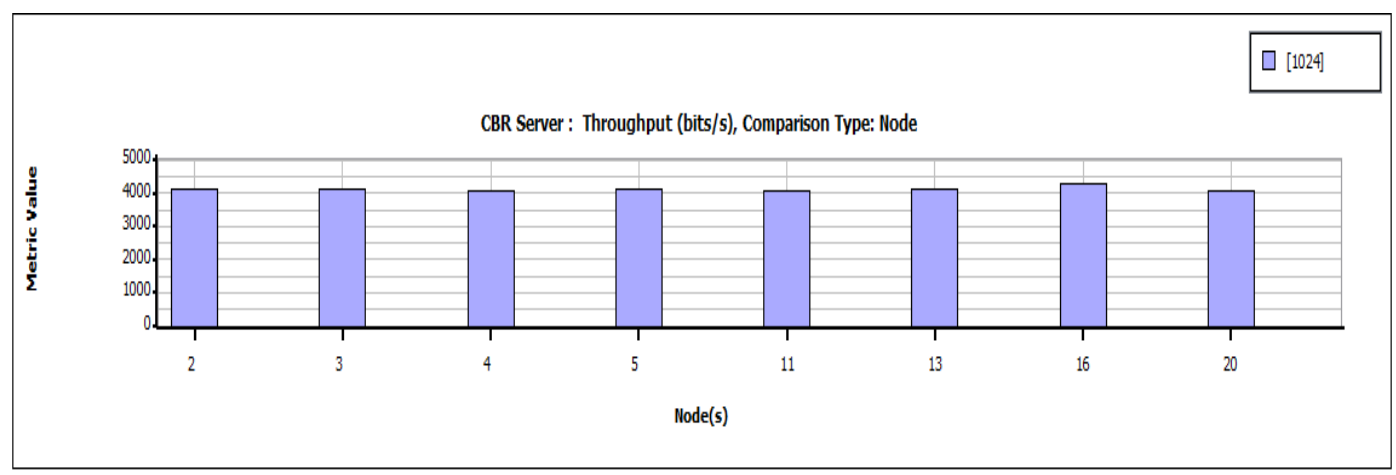

Figure 4. (B) Throughput (DYMO)

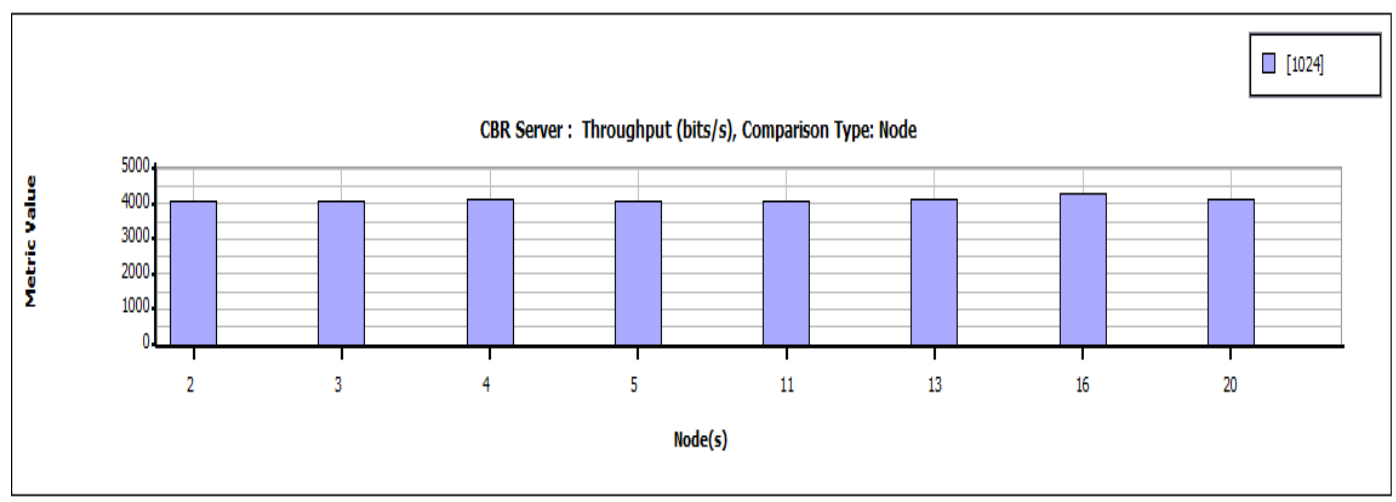

Figure 4. (C) Thrput (DSR)

\section{iii. Average end to end delay}

Average end-to-end delay is the average time in which packets send from sensor node to the base station. When sensor nodes send data to the base station then there should be problem due to congestion in the communication network By analysis of three routing protocol we find that the end to end delay is greatest in DSR as compared to the others which are very small [13]. Figure (5) Show Average end to end delay of three routing protocol AODV (In Figure 5 (A)), DYMO (In Figure 5 (B)) and DSR (In Figure 5(c)). 


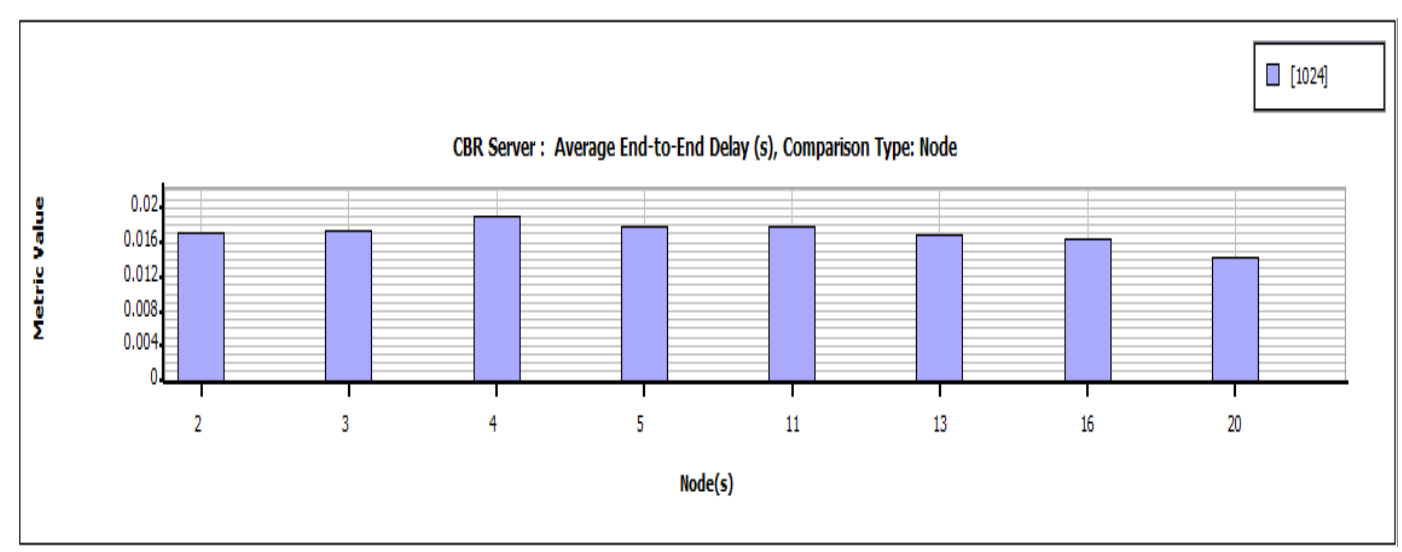

Figure 5. (A) Average End to End Delay (AODV)

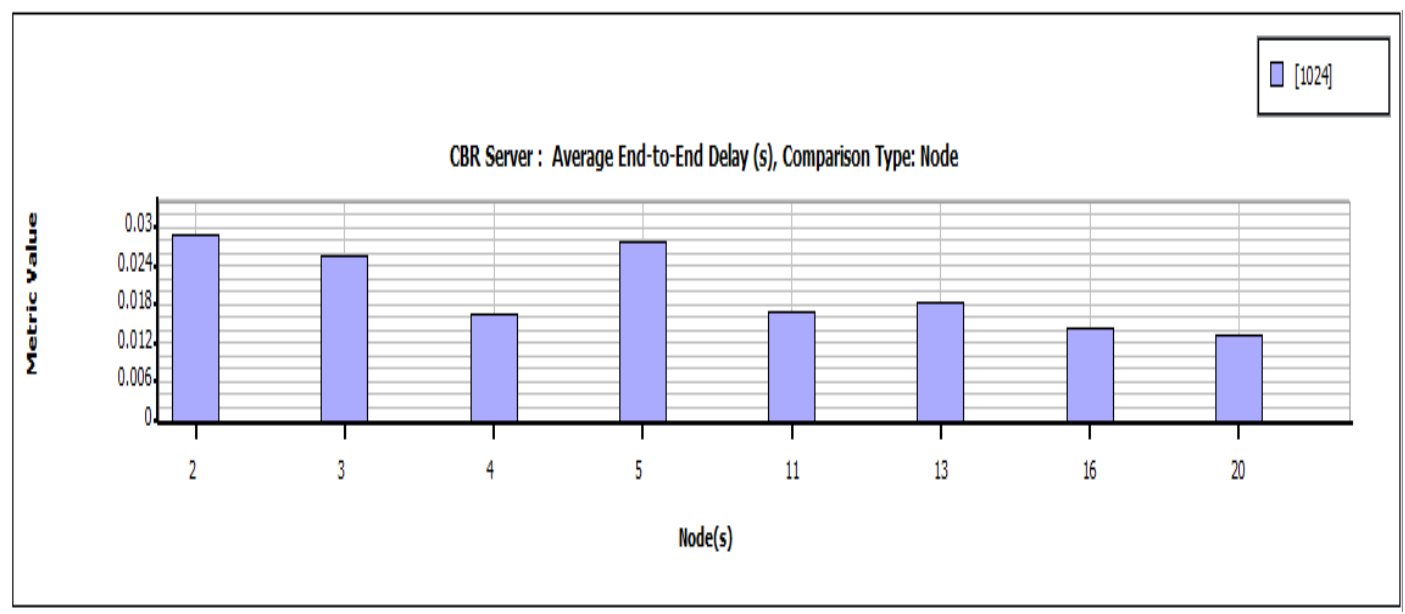

Figure 5. (B) Average End to End Delay (DYMO)

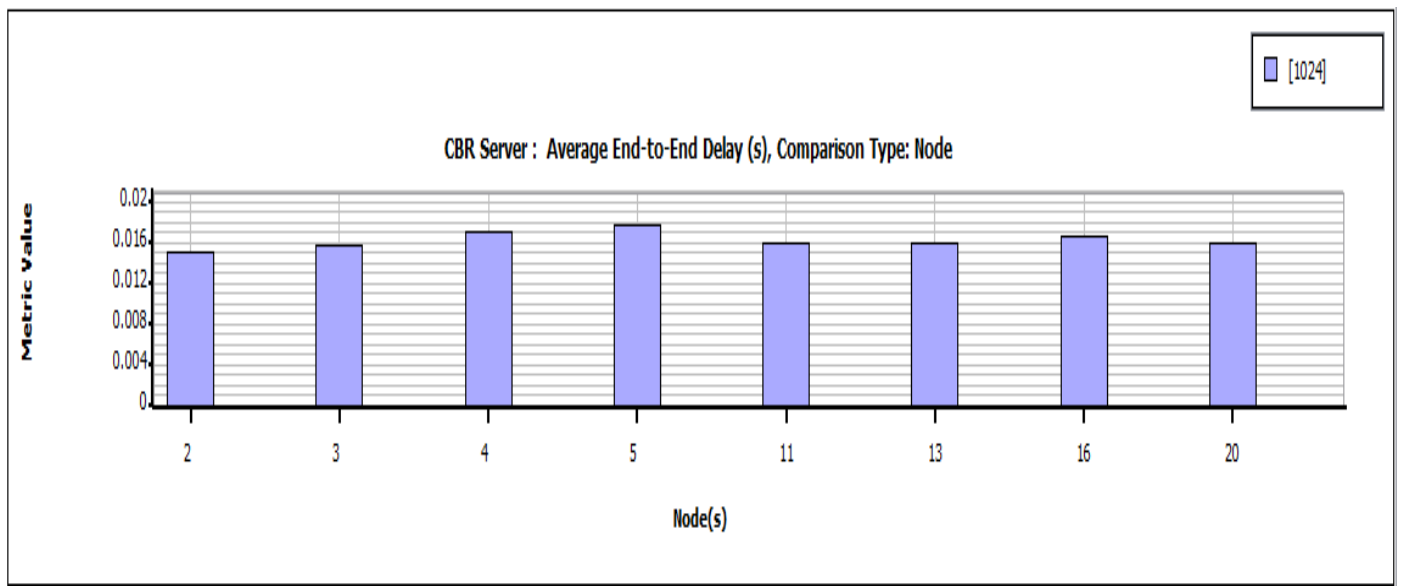

Figure 5. (C) Average End to End Delay (DSR)

\section{Conclusion}

Sensor nodes have low energy efficiency in Wireless sensor network. Energy efficiency is very big issue in wireless sensor network. In Wireless sensor network, routing protocols communicate data between sensor nodes and sensor nodes transfer sense data to the base station. This paper compares the three different routing protocol using same scenario of 20 sensor nodes. We have analysis performance of these routing 
protocols on the basis of performance matrices, Average Jitter, throughput (bits/s), Average End to End delay(s). By this analysis we find that DSR is less Energy efficient as compare to the other two routing protocol DYMO and AODV. In future work we will develop a cross-layer design approach that will be more energy-efficient as compare to traditional layered approach and other routing protocols.

\section{Acknowledgment}

Our special thanks to Prof (Dr.) K.K.Raina, Vice-chancellor, DIT University, Dehradun for his support and guidance.

\section{References}

[1] A. A. Abbasi and M. Younis, "A survey on clustering algorithms for wireless sensor networks", Computer communication, vol. 30, (2007), pp. 2826-28410

[2] I. F. Akyildiz, "Wireless sensor networks: a survey", Computer Networks, vol. 38, (2002), pp. 393-422.

[3] C. S. Rammurty and B. S.Manoj, "Ad hoc wireless networks architectures and protocols", (2014).

[4] S. K. Sarkar, T. G. Basavaraju and C. Puttamadappa, "Ad hoc Mobile Wireless Networks Principles, Protocols and Applications", (2008).

[5] B. Gupta, "Mobile Computing Technology, Applications, issues and research directions", [6] John Jubin and Janet D.Tornow[January 1987], the DARPA Packet Radio Network Protocols", Proceedings of the IEEE”, vol. 75, no. 1, (2008), pp. 21-32.

[6] The Qualnet (5.0.3) simulator www.scalable-networks.com.

[7] S. Murthy and J. J. Garcia-Luna-Aceves, “An Efficient Routing Protocol for Wireless Networks”, ACM Mobile Networks and App. Journal, Special Issue on Routing in Mobile Communication Networks, (1996) , pp. 183-97

[8] M. Amin, M. Abrar, Z. K. Abdusalam and S. Rizwan, "Comparison of OLSR \& DYMO Routing Protocols on the Basis of Different Performance Metrics in Mobile Ad-hoc Networks", American Journal of Scientific Research, ISSN 1450-223X, iss. 37, (2011), pp. 34-57.

[9] S. Mittal and P. Kaur, "Performance Comparison of AODV, DSR and ZRP Routing Protocols in MANET's", 09 International Conference on Advances in Computing, Control and Telecommunication Technologies, IEEE, (2009).

[10] S. V. Goyal and D. K. Jhariya, "Simulation and Performance Analysis of Routing Protocols in Wireless Sensor Network using Qualnet", International Journal of Computer Application (0975-8887), vol. 52, no. 2, (2012).

[11] N. Bisht, R. Mishra and R. Dhillon, "Mobility Based Performance Analysis of Wireless Sensor Networks", International Journal of Computer, Electronics \& Electrical Engineering (ISSN: 2249-9997), vol. 2 , iss. 2.

[12] Z. J. Haas, M. R. Pearlman and P. Samar, "Interzone Routing Protocol (IERP)", June 2001, IETF Internet Draft, draft- ietf-manet-ierp-01.txt.

[13] A review of current routing protocols for Ad- hoc mobile wireless networks by Elizabeth M. Royer, department of electrical and Computer Engg. ,California and C.K.Toh, IEEE Personal Communications April 1999, vol. 6, iss. 2, (1999), pp. 46-55.

[14] Z. Fan, G. Kalogridis, C. Efthymiou, M. Sooriyabandara, M. Serizawa and J. McGeehan, "The New Frontier of Communications Research: Smart Grid and Smart Metering”, e-Energy '10, Passau Germany, (2010).

[15] D. Vir, S. K. Agarwal and S. K. Imam, "A simulation study on nodes energy constraints of routing protocols of mobile ad-hoc network use of Qualnet simulator", international journal of advanced research in electrical, electronics and instrumentation engineering (IJAREEIE), vol. 1, iss. 5, (2012), pp. 401-410.

[16] A. Narmada and P. S. Rao, "Performance Comparison Of Routing Protocols For Zigbee Wpan", IJCSI International Journal of Computer Science Issues, vol. 8, iss. 6, no 2, (2011), pp. 394-402. 


\section{Authors}

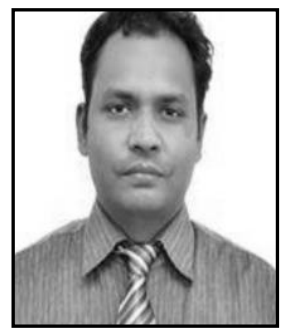

Rakesh Kumar Saini, he received the MCA degree from UPTU, Lucknow, India in 2005 and M.Tech (Computer Science and Engineering) degree from UTU, Dehradun, India in 2012 and Pursuing PhD from DIT University, Dehradun, India in 2014.He is having 12 Years of teaching experience. He is author of around 10 books. His research interests include Wireless Sensor Network, Energy-Efficiency in Wireless Sensor Network.

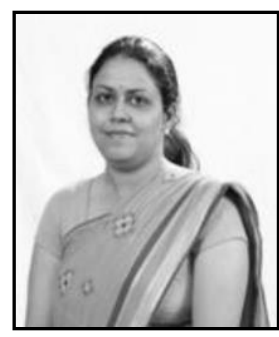

Ritika, she received the Ph.D. degree in Computer Science from GKU, University, Haridwar in the year 2010, M.Tech degree in Computer Science and Engineering from UTU, Dehradun and MCA from GKU Dehradun. She is life time membership of ISCA, CSI, IEEE, IAENG, ISCA and IETE. She was Chairman of Computer Society of India Dehradun Chapter in the year 2013. She specializes in core areas of computer science and holds experience of more than 14 years. 